\title{
¿Amor sin vínculo? En torno a la sexualidad y el amor en Lima
}

\section{RESUMEN}

El presente trabajo discute las formas sociales cómo se experimentan la sexualidad y el amor en Lima, a partir de un diálogo con otros libros, sobre todo con el trabajo del sociólogo peruano Pedro Pablo Ccopa (2011). Se presentan nuevas interpretaciones —desde una mirada sociológica — sobre los fenómenos de el sexo en los hostales y hoteles; y sobre el reguetón/'perreo' como baile moderno y simulacro sexual. El autor llega a conclusiones respecto al tema señalado que: i) se requiere hacer delimitaciones adecuadas en torno a la población estudiada para una mejor comprensión del fenómeno así como una posible generalización; ii) las nuevas formas sociales sin compromiso — choque y fuga, el perreo, amigos con derechos, remember — son básicamente formas sexuales, no formas amorosas; iii) por tanto, las formas sexuales no terminan poniendo en cuestión la concepción de amor en el mundo contemporáneo (amor-romántico); iv) no se trata de una liberalización del Eros, sino de su agonía en nuestra época.

Palabras Clave: amor; sexo; emoción; ciudad; eros; modernidad; hostal; reguetón

\section{Love without link? On sexuality and love in Lima}

\begin{abstract}
The article discusses the social forms which sexuality and love are experienced in Lima, in dialogues with the specialized literature, especially with the last work's peruvian sociologist Pedro Pablo Ccopa (2011). New interpretations are presented -from a sociological view- on the phenomena of sex in hostels and hotels; and about reggaeton/'perreo' as modern dance and sexual simulation. The author concludes that: i) it's necessary to adequate delimitations about studied society in order to better understand the phenomenon as well as a possible generalization; ii) the new social forms without commitment — 'choque y fuga', perreo, 'friends with rights', remember — are basically sexual forms, not love forms; iii) so, sexual forms do not critic the idea of love in contemporary world (romantic love); iv) it's not a liberalization of Eros, instead, it's an agony.
\end{abstract}

KeYwords: Love; Sex; Emotion; City; Eros; Modernity; Hostel; Reggaeton 
Dormimos juntos, tiramos maravillosamente bien y nunca voy a olvidar su cuerpo moreno, cálido y firme.

Pero no es amor lo que nos une Alejandro Zambra (2011)

$\square$ amor y la sexualidad son dos experiencias inmanentes de los individuos; sin embargo, estas no se han vivido de la misma forma. Nuestras percepciones, nuestra moral, criterios de selección y formas de sentir han cambiado. Incluso las condiciones de la modernidad han variado, lo cual ha influido en la misma experiencia de vincularnos afectivamente entre nosotros. Estas transformaciones han sido abordadas por las ciencias sociales y las humanidades. Empero los análisis han venido siendo a escala mundial, mayormente teniendo como referencia las experiencias de los países del norte. ¿Será que las transformaciones se dan en el mismo grado y formas a escala latinoamericana? ¿Podemos encontrar formas particulares en nuestra región? Incluso es posible pensar en nuestra realidad peruana o limeña. El sociólogo Pedro Pablo Ccopa ha desarrollado una línea de investigación sobre las nuevas configuraciones en la sexualidad y la intimidad. En uno de sus últimos trabajos, Ccopa (2011) nos presenta una serie de ensayos sobre los cambios en la sexualidad y el amor en la Lima contemporánea. "Qué de nuevo ha aparecido en la sexualidad en las últimas décadas en nuestro país» (13). Con ello se empieza a discutir con las teorías acerca de estas transformaciones en relación a las formas locales [de vínculos humanos afectivos y/o sexuales].

\section{La sexualidad de hostal: la visibilidad de la sexualidad y la invisibilidad de la rutina}

El autor aquí nos presenta los cambios que ha experimentado la ciudad en torno al espacio en donde se dan las múltiples formas sexuales, como por ejemplo la sexualidad extramatrimonial. Se pasó del motel al hotel y finalmente al hostal (en su forma final de uso generalizado), el cual se ha expandido por toda la ciudad y ha terminado siendo un indicador de la visibilización y democratización del sexo (Ccopa, 2011, p. 15). En ella se configura un nuevo tipo de sexualidad, que el autor la llama sexualidad de hostal. La sociedad limeña va dejando la clandestinidad de sus bajas pasiones para vivirlas a plenitud del día.
Este tipo de sexualidad se caracteriza, según el autor, por una sensación de plenitud, por su privacidad y apartamiento del mundo público. Así, los hostales son espacios para las aventuras y lo extramatrimonial. La figura del amante es central en la sexualidad de hostal; la clandestinidad es su modalidad. Sin embargo, hay un espectro más amplio de relaciones, más allá de la aventura y las relaciones prohibidas. Uno, las relaciones estables y no matrimoniales (comprometidas como los enamorados) también acuden a los hostales. Los hostales no se reducen al lado oscuro de la «doble vida», como si fuera una premisa que todas las personas emparejadas tienen una relación oficial y otra informal (llámese «trampa»). En otras palabras, las parejas estables y formales también acuden a los hostales (y hoteles). De modo que la proliferación en el uso de hostales y hoteles se han expandido no sólo para relaciones clandestinas y extramatrimoniales, sino para que las parejas no-matrimoniales canalicen su sexualidad cuando no tiene un lugar para ello.

Dos, las relaciones no matrimoniales y extramaritales también experimentan la rutina en su quehacer sexual. Todo tipo de vinculación sexual experimenta varios momentos: siendo uno de ellos la novedad en cuanto a la presentación y sincronización del encuentro sexual; otro viene a ser a los momentos de aprendizaje en donde incorporan nuevas prácticas en su intimidad; y el perfeccionamiento de ciertos ángulos que permiten un mayor goce. Empero, una pareja — sea formal o no- llega a tener una serie de prácticas sexuales que van sedimentándose con el tiempo hasta el punto de llegar a tener una rutina sexual, es decir una serie de prácticas sexuales regulares. Lo cual no implica que no haya momentos de reinvención. Pero, finalmente, se trata de la rutina en las cuatro paredes. De modo que pensar que las relaciones no matrimoniales y extra-matrimoniales escapan de la rutinización es un punto discutible. La sexualidad de hostal no es, per sé, como diría el autor, anti-rutinaria.

La experiencia amorosa está matizada por otros factores como el tiempo, el dinero y el lugar. La pareja va conociendo — de acuerdo a la disponibilidad de tiempo y recursos económicos - la oferta de hostales y hoteles; sobre todo este último: los hoteles ofrecen una mayor variedad de habitaciones para el despliegue sexual: que van desde una habitación clásica o con jacuzzi; o una habitación llena de espejos; o una habitación con iluminación tipo discoteca. No obs- 


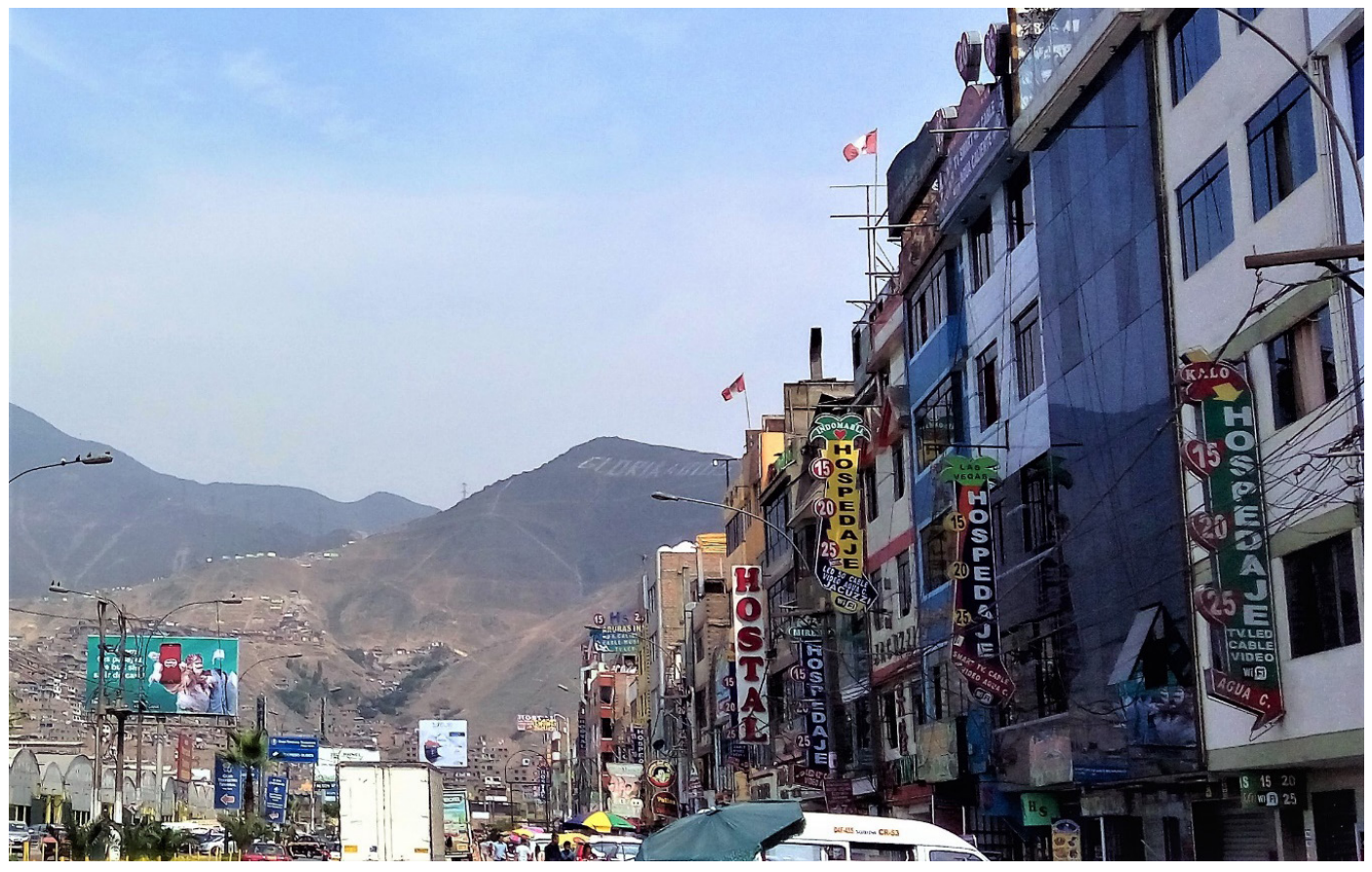

FIGURA 1: Proliferación de hostales en Lima Norte Fuente: () Piero Ochoa Valdez (2018) (Av. Tomás Valle, cdras. 3 y 4 , distrito Los Olivos)

tante, en medio de esta variedad y en el transcurso de la relación, la pareja va descartando unos y prefiriendo cierto tipo de habitaciones y, por lo tanto, de hoteles (o hostales). Así, más allá de lo que ocurre entre las cuatro paredes, toda la ruta de selección se estabiliza también. La propia selección del espacio rutiniza el encuentro (no matrimonial o extramatrimonial). En suma, la rutinización tiene una mayor expansión; la rutinización va más allá: desde la práctica sexual hasta la selección de las «cuatro paredes».

\section{La desinhibición sexual generalizada}

Por otro parte, en el texto se enfatiza a la mujeramante: como un sujeto que bajo el techo de un hostal/hotel se desinhibe sexualmente, dejando atrás la faceta que le exige el mundo del trabajo o la familia. Efectivamente, en la habitación de un hostal/hotel se da un mayor desenfreno sexual a diferencia de la habitación del hogar. Ccopa vincula a ello cierto grado de moderación gestual que se da en la práctica sexual dentro del hogar, pues en ella se conviven: o con familiares (hijos, padres, abuelos) en su interior o con vecinos alrededor (ya sea en un barrio, quinta, o departamento). O con ambas. Por eso la pareja se controla en cuanto a la emisión de sonidos, ya sean los que emiten sus propios cuerpos o por el movi- miento del soporte material sobre el cual se realiza el encuentro. Incluso en esta situación, la pareja utiliza artefactos de audio o video para generar «ruido» que opaquen los sonidos del propio acto copulatorio. En cambio, en una habitación de hostal/hotel, hay una mayor tendencia a la despreocupación en torno a la emisión de sonidos amatorios.

La regulación sonora básicamente se entiende por el principio del lugar habitado. En el hogar, el individuo o la pareja tiene un mayor control del sonido amatorio debido a que es el lugar que habitan (con regularidad). Al ser el lugar que habita, este tiene un mayor cuidado del propio espacio: no solo con la emisión de sonidos sino también sobre la materialidad sobre la que se despliega el encuentro sexual (el piso, las sábanas, las paredes, etc.). Además, el lugar propio habitado genera un reconocimiento por parte de la comunidad más cercana. Por el contrario, el hostal/hotel es un lugar no propio, no habitado que no implica un cuidado del mismo, así como también las parejas-usuarias se mantienen en un anonimato frente a las demás parejas con quienes comparten el piso. En ellos no hay cuidado del espacio habitado ni control de sus cuerpos, pues todo fluye sin preocupación. Anonimato y desenfreno. En síntesis, el control varía según la cercanía del espacio habitado (que va desde el lugar propio hasta la habitación alquilada). Bajo esa correlación entre control y el lugar habitado, 
la experiencia sexual varía. De modo que en el hostal/ hotel se afirma más la imagen de mujer-amante (y también la del hombre-amante), que en la habitación del hogar.

No obstante, ello no implica que solo se afirma el desborde sexual de la mujer (para seguir con la línea específica que plantea el autor). No solo hay desinhibición sino también hay repetición y sedimentación. ¿La mujer-amante (sea la pareja formal o la amante informal) puede escapar de la rutina? El hostal/hotel es un espacio de transformación del performance sexual. En un encuentro sexual cada individuo tiene consigo un conocimiento sexual, un grado de expertise. En ese punto Ccopa afirma de manera dicotómica dos cosas: i) mientras la fidelidad mantiene la rutina sexual de la pareja, la infidelidad lo permuta; ii) que en el hotel se afirma la mujer-amante en la innovación y novedad; en el hogar no. La infidelidad y el hostal/hotel escapan de toda rutina. Cuando alguien tiene un amante, después de un número de encuentros, ya puede decir: «las cosas que con ella hace en la cama», "las cosas que le gusta que ella le haga». En otras palabras, podría contar cómo suele ser regularmente el despliegue sexual que llevan a cabo entre las cuatro paredes. Todo ello evidencia una rutina: una serie de prácticas sexuales que se repiten. En esa convergencia de cuerpos, expertise y pulsiones, los amantes van regularizando ciertas formas de su práctica sexual. Por lo tanto, la rutina no escapa a la figura de la mujer-amante, que se afirma en los lugares no habitados como los hostales y hoteles.

\section{«Choque y fuga» como pura sexualidad}

Este tipo de relación consiste en un encuentro sexual casual, que "dura lo que dura su consumo" (Ccopa, 2011, p. 67); un encuentro en donde las personas se conocen y al día siguiente se olvidan. Ccopa califica a esta forma social como una representación del amor. Veámoslo en palabras del autor:

No es que los jóvenes modernos quieran desprenderse del amor. El individuo humano no podría prescindir del amor. El amor es una necesidad básica que establece un vínculo emocional de a dos. Es uno de los dos sentimientos básicos que posee el ser humano (el otro es la muerte o el odio). Lo que se quiere es cambiar el contenido del amor. Así cómo la comida para ser mejor degustada necesita ser mejorada, lo mismo se desea para los afectos. El amor, para brindar una mayor felicidad, en el contexto actual, debe cambiar su carácter romántico, posesivo y sufriente por otro menos posesivo, menos arrebatador, más lúbrico, con una combinación de razonamiento y emocionalidad (Ccopa, 2011, p. 73).

El autor señala que en el mundo contemporáneo el amor resignifica su contenido, dejando sus características posesivas y absorbentes a unas con más margen de autonomía entre la pareja. Empero, el «choque y fuga» no presenta la característica de vínculo afectivo, de involucramiento con el otro. Por el contrario, es lo más evanescente que puede haber entre los individuos. No tiene pretensiones de largo plazo. Es vivido intensamente, pero queda sólo como anécdota. Su propósito básico es la satisfacción sexual espontánea. Lo espontáneo del presente se renueva todos los días y su alcance se da esporádicamente, de modo que el vínculo entre los individuos no tiene necesidad de conservación. Ésta es la búsqueda pura de canalización de la pulsión sexual.

Por supuesto, hay otras formas de vínculo, que son menos demandantes como, por ejemplo, amigos con derechos y el remember. Pero estas formas no son vínculos sentimentales; más bien, se tratan de vínculos emocionales. Los sentimientos no son equiparables a las emociones: los primeros se caracterizan por su permanencia afectiva y su involucramiento con el otro; los segundos, por su intensidad afectiva y su fragilidad en su sostenimiento. Sentimientos como la confianza y el amor; emociones como la pasión y la ira. De modo que estas formas vinculantes que se mencionan líneas arriba no se caracterizan por los vínculos sentimentales, por lo tanto, no podrían ser vínculos amorosos. Son formas que se distancian del amor para la celebración directa de la sexualidad, del placer sexual. En otras palabras, se trata de vínculos sexuales, no amorosos.

El amor no se puede reducir a la sexualidad. No son lo mismo. Ambos elementos se relacionan, pueden ir juntos, pero no significan lo mismo. Las características que presenta el amor como un sentimiento hacen que difieran de otros vínculos afectivos. No se trata de dejar a un lado la precisión conceptual y las tradiciones sobre las cuales se discuten. Sin ellas, 
«amor» podría significar cualquier vínculo. Incluso aquellas formas frágiles que menciona Bauman (2005).

Otro aspecto que señala la cita del texto es la búsqueda de nuevas formas de vínculos de pareja, que se desmarquen de "lo posesivo y sufriente». ¿Esta búsqueda de un amor más libre y lúbrico puede ser encontrada fuera del amor romántico? Ccopa encuentra una respuesta en las formas no amorosas que viene registrando (la amante, amigos con derechos, el remember), formas que escapan al compromiso y al vínculo sentimental. Sin embargo, podemos encontrar otra forma de amor en el mismo amor romántico. Denegri (2008) nos habla del amor diligente, que a diferencia del amor pasional, es un amor cuidadoso, atento y responsable. Se caracteriza también por su carácter reflexivo, el cual busca involucrarse con la pareja, pero sin buscar encorsetarlo, suprimiendo su libertad e individualidad. ${ }^{1}$ Podría decirse que es una variación dentro del modelo del amor romántico; una variación dentro de las formas amorosa. No obstante, implica un grado de madurez tanto personal como de pareja. Un matrimonio podría tener toda una larga vida sin llegar a experimentar el amor diligente. ${ }^{2}$

Finalmente, es necesario preguntarnos si esta búsqueda se da en forma generalizada. ¿La necesidad de nuevas formas de vinculación sexual son buscadas por todos los individuos sin diferenciación de edad? ¿Aquellos atajos para el encuentro sexual son una apuesta generalizada de los individuos? Como se ha señalado, no se trata de nuevas formas amorosas, sino de formas sexuales. En este punto, la estratificación por edad es una delimitación que nos permite comprender las variaciones que se dan en la experiencia sexual y amorosa. No es lo mismo la aproximación de los jóvenes que la de los adultos. En principio, los jóvenes se encuentran frente a la novedad de los fenómenos y por lo tanto a lo desbordante del mismo. Podemos ver en ellos una inclinación más a la experiencia sexual, que la amorosa. Por eso, una gran parte de ellos practican formas de vínculos sexuales distantes al compromiso,

1 El amor pasional es posesivo y experimentado como atadura. Véase Denegri (2006).

2 La seguridad personal, la autoestima, el autoconocimiento, la reflexividad y el aprendizaje son elementos importantes para desarrollar este vínculo sentimental. saturación y exclusividad del amor romántico. Por otro lado, se tiene otra tendencia dentro de los jóvenes que sí experimentan el amor romántico. A ellos podemos verlos absorbidos entre esa mezcla entre sexo y amor que los lleva el propio descubrimiento de la misma. ${ }^{3}$ En ambos perfiles de jóvenes, la experiencia es intensa, sea tan solo sexo (en sus formas de choque y fuga, remember o amigos con derechos, o salientes) o en la forma de enamorados.

La situación es distinta en el caso de los adultos, pues la experiencia dosifica el establecimiento de nuevos vínculos amorosos o sexuales. En efecto, la experiencia acumulada los lleva a ponderar lo que ellos buscan o experimentan en su presente. Pero, además, ocurre algo importante, un gran sector de adultos busca realizar el ideal de familia y matrimonio. El matrimonio tanto civil como religioso sigue siendo un referente de realización adulta (véase Tabla 1). Las formas de acceso al matrimonio civil tanto personalizada para las clases medias y populares son recurrentes. Incluso, los municipios organizan matrimonios civiles masivos, que tienen un bajo costo, que tienen como usuarios del servicio a parejas de clases populares de bajos recursos económicos. Ello indica una apuesta por el matrimonio en los sectores populares de la ciudad. En general, se aprecia que en la adultez hay una gran tendencia por la apuesta por el amor romántico. Los individuos en edad adulta afirman las formas tradicionales de emparejamiento. Si bien, en su juventud, los individuos pueden apostar por formas más abiertas de vínculo sexual, en la adultez, los mismos terminan emparejándose bajo vínculos tradicionales. En síntesis: si miramos bajo la segmentación por edad, el matrimonio y el amor romántico no se encuentra en crisis; que la juventud busque nuevas formas no sentimentales no implica que ello se extienda a los individuos de edad mayor. La estratificación nos ayuda a diferenciar experiencias y ver sus alcances de generalización.

3 La intensidad del amor juvenil del siglo xxi es el tema central en películas recientes como Amar (Crespo, 2017) y Love (Noé, 2015); películas en donde el amor y el sexo se mezclan bajo el modelo del amor romántico, diferenciándose con las experiencias puramente sexuales, que también ocurren en las historias, y terminan reafirmando el vínculo amoroso. 
TABLA 1: Variación del número de matrimonios registrados (2005-2016)

Matrimonios registrados por vía ordinaria

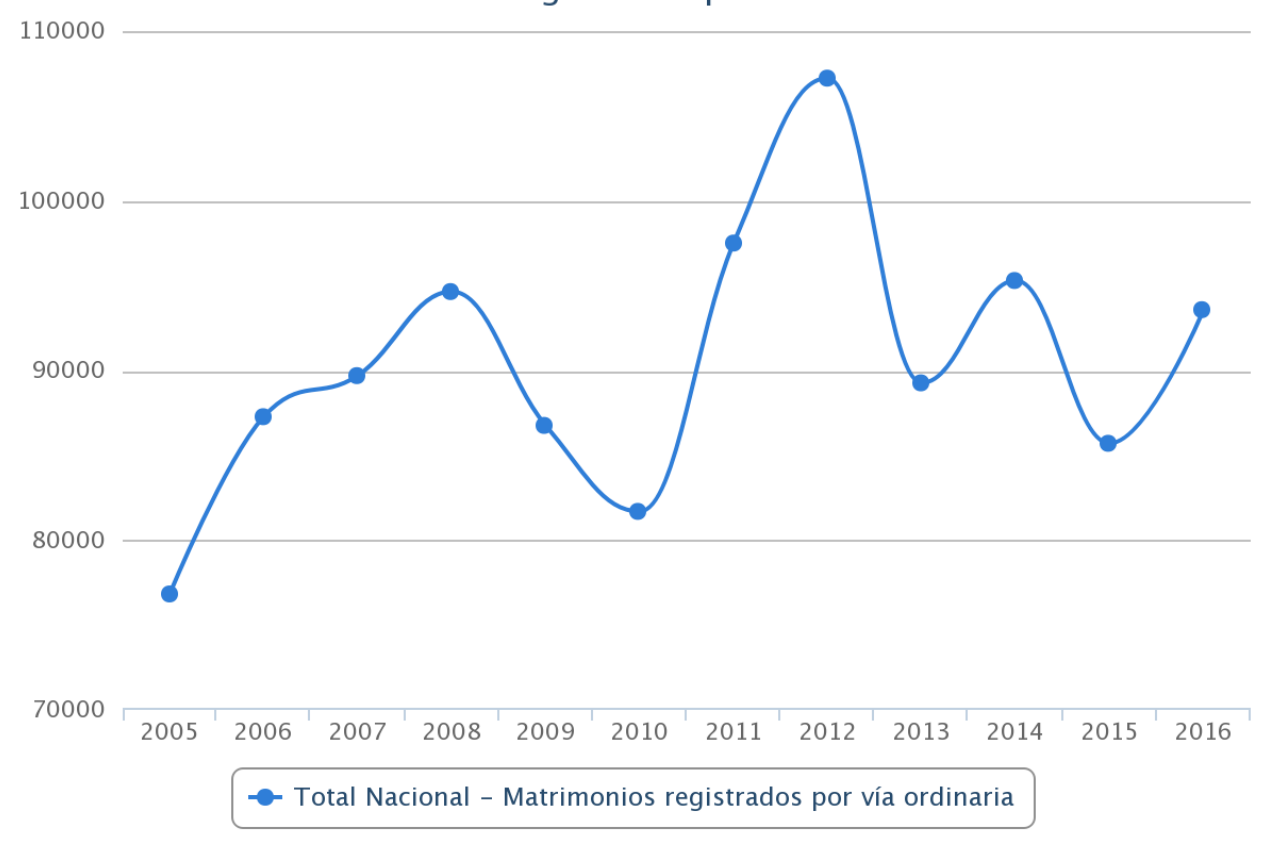

Fuente: RENIEC / INEI - Series Nacionales

\section{El perreo como simulacro sexual}

El baile es una forma de interacción entre los individuos bajo un tono festivo. Entre los diversos géneros, se encuentra el reguetón [o reggaeton], un género latinoamericano, el cual tiene al perreo como una de sus formas de baile. Esta es una danza bastante sensual y erótica, caracterizada por el movimiento del derrier femenino junto a la pelvis masculina, que repite movimientos parecidos a las poses sexuales. Por eso es considerado por Ccopa (2011) como un simulacro del acto sexual. En las palabras del autor, señala que este viene a ser una forma «donde se desacraliza el sexo y las relaciones entre los sexos». Además, se hace una "parodia de algo muy privado como la sexualidad» (2011, pp. 168-169).

Por otro lado, el autor sostiene que el perreo es parte de la "feminización del mundo", pues el protagonismo en el baile recae en la mujer. En efecto, podríamos dar cuenta de la determinación de la mujer, es decir, el mayor ejercicio de libertad de la mujer como un ejercicio de sensualidad individualizada, en relación a la pareja de baile. Ellas deciden bailar, mostrarse o aproximarse mucho más en público. En otras palabras, se ha amplificado el campo de acción de la mujer en el mundo. No sólo la mujer está ganando espacios antes vetados como el mundo del trabajo, sino hay un incremento del espacio público. Además, ha surgido una serie de cantautoras ${ }^{4}$ en este género que afirman la determinación de las mujeres, su poder de decisión en la seducción, en la elección de pareja, en asumir más responsabilidades en sus relaciones. En sus letras la mujer tiene iniciativa, objetiviza su cuerpo y el de los hombres. En el baile, la sexualidad y el amor, la mujer ecualiza sus posibilidades frente al hombre. Por tanto, se trata de una mayor ecualización entre los géneros en el siglo xxI. Desde el siglo xx la mujer ha venido ganando derechos políticos y sociales, un mayor reconocimiento del valor que genera en el mundo del trabajo moderno. La ecualización de género también se presenta en otros dominios de la vida social como en la música, el baile y la sexualidad. Incluso en el amor mismo: si en los tiempos antiguo y medieval el discurso amoroso y sexual estaba dirigido al hombre ${ }^{5}$, ahora en el

4 Entre ellas están Mara Parda, Farina, La Zista, hasta la más actuales Becky G, Natti Natasha, Leslie Grace, entre otras. Véase Ferrús (2016) y Sanchéz (2018).

5 Tanto la literatura de la Roma antigua y del hinduismo (antiguo), así como la literatura medieval europea como musulmana; toda esa literatura tiene como público sólo al hombre, como el único agente 


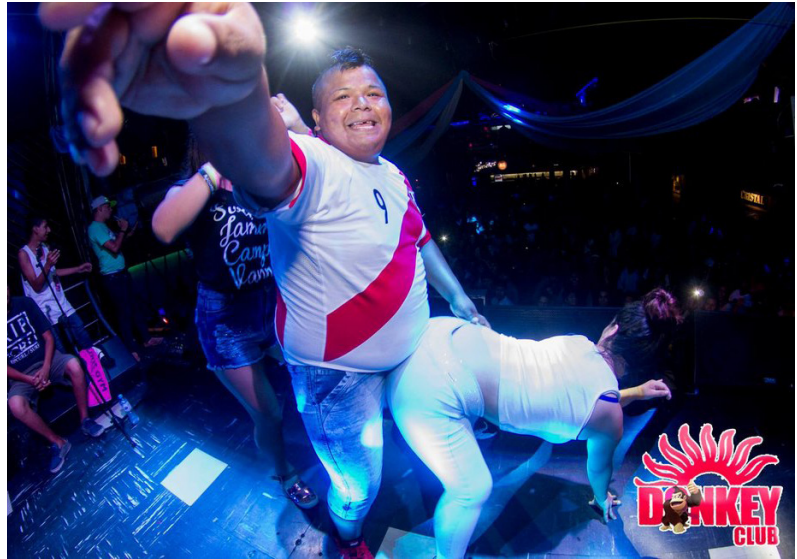

FIGURA 2: Baile del perreo en discoteca de Lima Sur.

Fuente: () Discoteca Donkey Club (2016) (Distrito San Juan de Miraflores, (C) Facebook)

mundo moderno la literatura especializada se ha expandido también hacia la mujer. No sólo hay literatura sobre estrategias de seducción, de conocimiento sexual femenino, sino también sobre técnicas de vida para el cuidado y reconocimiento del amor frente a sus peligros — desde la ficción hasta libros de no ficción como la crónica. Toda una literatura dirigida al público femenino.

Sin embargo, el autor soslaya que gran parte de las letras de este género así como la exposición de las mujeres en los videoclips tienen a la mujer como objeto sexual. En otras palabras, la oferta musical y visual del género sigue fetichizando a la mujer. En esa misma línea se da su correspondiente forma de baile: la mujer baila para el hombre como objeto sexual, ella adquiere valor en la medida en que haga bien su parte, mostrando y refregando su derrier. Si el perreo es un simulacro sexual en una sociedad machista, lo es en la medida en que ella se «mueve bien» (en el baile) como si fuera una extensión de la manera cómo «se mueve en la cama». En suma, vemos dos tendencias: por un lado, el reguetón mantiene una fechitización de la mujer; pero, a la vez, la elasticidad del género musical, también contiene líricas femeninas en donde las mujeres se afirman, ecualizando estas mismas posibilidades con los hombres. Por lo tanto, el reguetón no puede reducirse ni la fechitización de la mujer, ni a la feminización del mundo. La individualización

habilitado para experimentarla y reflexionar sobre ella. Véase el estudios comparativo de Villanueva (1998). del género musical le da posibilidades polivalentes (y contradictorias).

La seducción es una característica extendida en el baile moderno. ${ }^{6}$ Los grados son los que varían, pero regularmente se puede percibir una seducción femenina, así como masculina. Mientras se baila los cuerpos se pueden ir acercando. Por tanto, no es una característica propia y particular del perreo. Por lo explícito del roce de los cuerpos, el perreo es considerado un baile obsceno por el mundo adulto (y conservador). Tampoco es el único baile de ese tipo en el mundo contemporáneo. Se trata del daggering, que es la forma de baile del género dancehall, originariamente de Jamaica pero se va extendiendo como un baile caribeño, que se caracteriza por un movimiento mucho más frenético y violento en el contacto pélvico, que imita muchas más posiciones sexuales que el propio perreo. ${ }^{7}$ Incluso este tipo de baile también genera controversia en la sociedad jamaiquina, en donde un sector de la sociedad quiere prohibirla. Volviendo a Lima, si ahora es el reguetón y el perreo, antes lo fue la lambada en los noventas, la salsa sensual en los ochentas. La coquetería y la seducción es parte de la música y baile moderno. El perreo —así como el daggering — es el tipo de baile del siglo xxi.

Otra lectura sobre esta forma de baile en relación a la sociedad es la conversión de lo privado en público. El perreo hace de la sexualidad algo público (Ccopa, 2011, p. 169). Esta es una tendencia social de la modernidad que resalta Bauman (2004). El perreo vendría a ser uno de los varios bailes que celebran la sexualidad. Empero, en contraste con ello, Illouz sostiene lo contrario: la disolución de las barreras de lo público y lo [emocional] privado viene a ser una

6 La seducción viene a ser una forma de coquetería, pues no implica una disposición sexual inmediata de quien despliega esta acción. Por ejemplo, en el baile, cuando se perrea, los movimientos femeninos no suponen necesariamente que la mujer quiera tener un encuentro sexual con la pareja de baile. Tampoco supone que quiera que él la toque más de lo necesario: muchas veces mientras bailan los hombres van intentando tocar otras partes del cuerpo de la mujer como son los senos, la vagina, las piernas; sus manos intentan recorrer otras zonas del cuerpo femenino, pero ante ello la mujer retira sus manos bajándolas o subiéndolas hacia la cintura, que es la parte que le está permitida "agarrar». El perreo es un simulacro sexual que permite coger a la mujer sin que ello suponga necesariamente que la toque completamente ni que termine acostándose con ella. En ese sentido el perreo es una instancia de coquería en donde la mujer juega con una serie de seńales contingentes entre el sí y el no. Ello le resta otro matiz de novedad al perreo. Sobre la coquetería véase Simmel (1999).

7 Sobre el dancehall y el daggering como música y baile jamaiquino véase el documental de Galofré (2011). 
de las condiciones de la modernidad (Illouz, 2012, p. 27; 2007, p. 18). Leído así, el perreo no vendría a traer ninguna novedad en la vida social, sino tan solo sería una versión más explícita de una vieja tendencia. Sin embargo, más allá de cualquiera de estos supuestos de la modernidad, en Lima el perreo viene a ser, como señala el autor, una forma particular [contemporánea] en que la mujer sexualiza su cuerpo sin ocultarse.

\section{La celebración del Eros: ¿̨se libera o agoniza?}

El reino de los hostales, la proliferación de las relaciones sin compromiso, las formas de baile como simulacro sexual vienen a darnos cuenta, como sostiene el autor, de la liberalización del Eros, igual que es su libro precedente (Ccopa, 1999). Previo a este tiempo contemporáneo, la sexualidad, así como el amor, estaba constreñida a los valores tradicionales del mundo social. En otros términos, las relaciones de género se han ido reestructurando (Ccopa, 2011, p. 174).

No obstante, esta visión reduce al Eros a un deseo sexual. En un sentido figurado - siguiendo la tradición griega-, Eros hace referencia a la relación de amor entre los humanos. El filósofo Bung-Chul Han señala que Eros es «una relación con el otro que está radicada más allá del rendimiento y del poder» (2016, p. 22). Un tipo de vínculo que busca relaciones armoniosas entre los individuos, que escapen a las diversas formas de sujeción del poder (que aniquila al otro). Es la conversión/reducción del amor en sexualidad. El cuerpo se convierte en una mercancía, que se fetichiza. ${ }^{8}$ El individuo no es tratado como una persona, pues es fragmentado en objetos sexuales parciales. No se lo reconoce. ${ }^{9}$ En ese sentido, las nuevas formas de vínculos que describe Ccopa no representarían una liberación y extensión del Eros, justamente por su sentido objetivizante, instrumental, jerárquico, sin vínculo afectivo, sin compromiso y básicamente sexual. ${ }^{10}$ En esos términos, la proliferación de estas relaciones no refleja la erotización de

8 Por ejemplo, el perreo es un baile en donde la mujer se convierte en "perra». Lo cual expresa la impersonalidad sexual. Véase Ubilluz (2006).

$9 \quad$ Para el amor como acto de reconocimiento véase Rohmer (2012)

10 Ilouz (2007) señala que la instrumentalización y fechitización vienen a expresar el modo en que la vida emocional sigue la lógica del intercambio y las relaciones económicas. Las nuevas formas sexua- la sociedad sino su sexualización. Eros no se expande, sino agoniza. ${ }^{11}$

No olvidemos que en el siglo xx la sexualidad adquiere un mayor protagonismo pues siendo el deseo el centro de la subjetividad en medio de la sociedad del consumo, la sexualidad se convierte en la metáfora de aquella (Illouz, 2012).

\section{¿Declive del amor romántico?}

Finalmente, el autor nos narra un acontecimiento general dentro del fenómeno amoroso: la sexualidad se ha liberado bajo nuevas formas de amor. No obstante, este auge de nuevas formas - más líquidas- del amor, también supone una consecuencia lógica: el declive del amor romántico. El autor aquí presenta una concepción antinómica y excluyente para el análisis del fenómeno, pues supone que la presencia de algo nuevo conlleva el declive de lo viejo. Nos habla del declive del amor romántico (Ccopa, 2011, p. 47). ¿Pero acaso podemos decir que es realmente así? ¿Los individuos han dejado de casarse de forma masiva? ¿Las películas románticas han perdido en taquilla? ¿Los libros de amor han dejado de ser bestsellers? ¿Cuánta gente se sigue enamorando a nuestro alrededor?

Las historias de amor no han pasado de moda. En el mundo actual no podemos decir que en términos de rituales y consumo los individuos hayan dejado de vivir y respirar del amor-romántico. Ello nos llevar a discrepar con esa concepción binaria antagónica, pues el mundo es tan amplio y plural que hay bastante espacio para la coexistencia de diversas formas de amor, sin que una opaque a la otra.

Se da una coexistencia de las formas amorosas y las formas sexuales pues los individuos encuentran en alguna de ella, o en más de una, según la compatibilidad con su carácter y expectativas de la vida. Las experiencias amorosas son una forma de autoconocimiento, que nos lleva a identificarnos con una u otra forma de vínculo (un camino que nos lleva muchas veces a situaciones críticas y confusas).

les de vincularse vendrían a ser parte de la mercantilización de las emociones.

11 Marcuse tiene un sentido semejante en torno a Eros. Por eso habla de una posible transformación de la sexualidad en Eros en su versión utópica de la sociedad. Véase Marcuse (1983). 
En la escena contemporánea, vemos esfuerzos por teorizar las tendencias actuales ya sean caracterizándolas como modernidad o como posmodernidad. Si seguimos la línea del Ccopa, la condición de nuestro tiempo es la posmodernidad. Empero, la lógica de la posmodernidad no viene a ser una negación de la modernidad. Más bien, se trata de una noción más amplia de la modernidad, en la cual congrega dos vertientes, que son tanto un proceso de hipermodernización como de re-actualización de la tradición (Bericat Alastuey, 2003). Contrario a la mayoría de los autores que participan de este debate, no se cultiva una visión disyuntiva, sino una visión conjuntiva, de convergencia de tendencias en un mismo tiempo, que podemos considerar moderno o posmoderno. En ese sentido, las formas amorosas no vendrían a negar la condición posmoderna, si es que esta se afirma bajo sus formas sexuales (no amorosas). Las formas amorosas vendrían a ser ese componente que reactualiza la tradición, proceso que forma parte del cambio social de la escena contemporánea. Así, el amor romántico no tendría contradicción bajo la época posmoderna.

Bajo esa reformulación de la posmodernidad, mientras que las formas sexuales vendrían a ser la hipermodernización; las formas amorosas, la reactulización de la tradición. Por lo tanto, no podría confundirse las formas sexuales como formas amorosas de la posmodernidad, pues las formas amorosas responden a la otra fuerza de la época: la tradición.

\section{Conclusiones}

1. Los estudios sobre el amor deben tener delimitaciones, que permitan entender las variaciones del fenómeno. Entre las más importantes están los grupos etarios y la estratificación social, pues las experiencias amorosas y sexuales varían en estas. No es conveniente extrapolar la experiencia amorosa juvenil a toda la extensión humana de la época, pues los límites de esa experiencia están básicamente en los límites del grupo etario. Tampoco es apropiado pensar que las formas juveniles de exploración sexual o amorosa señalen la crisis del amor romántico, ya que esta última se sigue sosteniendo por las generaciones adultas. Las formas juveniles no rompen con las formas tradicionales, pues en general obedecen a mo- mentos de vida distintos de los individuos. Unos son jóvenes bajo formas exploratorias, los otros adultos bajo formas tradicionales. De la misma forma ocurre con la estratificación: el consumo de servicios de habitación varía según el nivel socioeconómico. Unos van a hostales, otros van a hoteles.

2. Para producir una mirada sociológica del amor debemos reconstituirla como una red de asociaciones, así como una experiencia individual unida a lo social (Piazzesi, 2015). Entre ellas podemos ver toda una ecología de soportes, que van desde una serie de formas de código amoroso (Luhmann, 1987), las instituciones que sostiene la experiencia amorosa (Coontz, 2006; Illouz, 2012), y los procesos de diferenciación por estratificación social. La mirada sociológica acerca del amor tiene que ver, por un lado, con una sociología de los soportes; y por otra, una apuesta por la socialización que se da entre individuos para el encuentro sexual, bajo ciertas variables que van más allá del cuerpo (grupo de pares, el estrato social, la edad, el alcohol, la ciudad/región). El fenómeno de la sexualidad implica mucho más que la erotización (o lo que en otro texto el autor denomina «sexocialidad»). ${ }^{12}$

3. La proliferación de hostales y hoteles representan básicamente el tener un espacio para la consumación sexual de pareja. Antes sólo el matrimonio gozaba de un espacio para la sexualidad, en cambio desde hace unas décadas, con la expansión de los hostales y hoteles, las formas no-matrimoniales tienen un espacio para el vínculo sexual. Las parejas no concretan la sexualidad con el matrimonio, sino que lo pueden concretar fuera o antes del mismo. Y estos espacios (acondicionados para el encuentro sexual) de la oferta privada lo canalizan. No se trata de la novedad de las relaciones fuera del matrimonio, de los remember, de los choques y fuga, sino más bien del énfasis en la renovación de los soportes materiales para el ejercicio de la sexualidad.

4. El reguetón ha tenido, en general, dos vertientes líricas: una, fechitización a la mujer desde la

12 La sexocialidad es una concepto creado por Ccopa para hacer referencia a «los elementos subyacentes tanto emocionales, subjetivos y actitudinales que vuelven más explosivo el goce sexual» (2009, p. 217). 
mirada masculina; la otra, le da protagonismo y mayor libertad de la mujer en el ejercicio de su sexualidad. No se trata de una relación antagónica de ambas tendencias; no se puede afirmar uno, negando la existencia de lo otro. El fenómeno del reguetón abarca más de un sentido, e incluso los puntos en que convergen. Tanto el género como su forma de baile, el perreo, tienen una significación más amplia y contradictoria, en donde las interpretaciones se dan de forma paralela.

5. El surgimiento del reguetón/perreo, la proliferación de hostales y hoteles, y las formas no convencionales de emparejamiento sin compromiso o fugaces no significan una erotización del mundo, sino más bien el declive del mismo: el declive del Eros. Las relaciones que se han venido registrando bajo las formas del remember, choque y fuga y el perreo se caracterizan más bien por la objetivación del cuerpo y la afirmación de la sexualidad en un sentido hedonista. Ello no hace referencia a la figura del Eros, que más que interrelaciones emocionales, tiene que ver con vínculos sentimentales. La preminencia de las formas de encuentro sexual va ligada a lo emocional. En ese sentido, el reino de la sexualidad/emocional no es el reino del Eros.

6. Las formas de vínculo sexuales se diferencian de las formas amorosas. Incluso esa diferencia se acentúa si lo pensamos bajo el horizonte de la posmodernidad, pues esta época alberga en ella dos vertientes - la hipermodernización y la reactualización de la tradición—; de manera que el amor romántico sigue teniendo un lugar en este tiempo, sin contradecirse con la coexistencia de formas puramente sexuales. Por lo tanto, el amor romántico no requiere la crisis como condición existencial bajo el paraguas de la posmodernidad. Las formas modernas de amor continúan en la posmodernidad. 


\section{Bibliografía}

Bauman, Z. (2004). Modernidad líquida (3ra ed.). Buenos Aires: FCE.

Bauman, Z. (2005). Amor líquido: acerca de la fragilidad de los vinculos humanos. México D.F.: FCE.

Bericat Alastuey, E. (2003). Fragmentos de la realidad social posmoderna. REIS, (102), 9-46. https://doi. org/10.2307/40184535

Ccopa, P. P. (1999). Eros liberado: hostales y sexualidad en la Lima de los noventa. Lima: T-Copia.

Ccopa, P. P. (2009). Avisos de servicios sexuales y fantasias: arquetipos, imaginarios y cultura en la ciudad (Tesis Doctoral en Ciencias Sociales). UNMSM, Lima.

Ccopa, P. P. (2011). Amor y sexo en la ciudad: imágenes mundanas. Lima: Colegio de Sociólogos del Perú.

Coontz, S. (2006). Historia del matrimonio: cómo el amor conquistó el matrimonio. (A. Bixio, Trad.). Madrid: Gedisa.

Crespo, E. (2017). Amar. España: Avalon-FILMEU. Recuperado de http://www.imdb.com/title/ tt5479616/

Denegri, M. A. (2006). La problematicidad del amor. En De esto y aquello (pp. 27-36). Lima, Perú: Universidad Ricardo Palma, Editorial Universitaria.

Denegri, M. A. (2008). Amare y dilígere. En Hechos y opiniones acerca de la mujer (pp. 269-270). Lima: San Marcos.

Ferrús, J. (2016, febrero 16). Mujeres cantantes de reggaeton. Recuperado el 21 de octubre de 2018, de https://www.lavanguardia.com/muyfan/20160215/302186057308/mujeres-cantantesreggaeton.html

Galofré, M. (2011). Hit Me with Music. España: Nice time. Recuperado de http://www.imdb.com/title/ tt1830630/

Han, B.-C. (2016). La agonía del Eros. (R. Gabás, Trad.). Barcelona: Herder.
Illouz, E. (2012). Why love hurts: a sociological explanation. Cambridge, U.K.; Malden, M.A.: Polity Press.

IlLuOZ, E. (2007). Intimidades congeladas: las emociones en el capitalismo. (J. Ibarburu, Trad.). Buenos Aires: Katz Editores.

LuHMann, N. (1987). El amor como pasión: la codificación de la intimidad. Barcelona: Península.

Marcuse, H. (1983). Eros y civilización; una investigación filosófica sobre Freud. (J. García, Trad.). Madrid: Sarpe.

NoÉ, G. (2015). Love. Recuperado de https://www.imdb. com/title/tt3774694/

Piazzesi, C. (2015, noviembre). Producir una mirada sociológica sobre el amor. Revista Latinoamericana de Estudios Sobre Cuerpos, Emociones y Sociedad, 18(7), 8-18.

Rohmer, S. (2012). Amor, el porvenir de una emoción. (G. Menéndez, Trad.). Barcelona: Herder. Recuperado de https://es.scribd.com/book/351481561/Amor-elporvenir-de-una-emocion

SANCHÉz, A. (2018, marzo 6). Las mujeres del reggaeton: Becky G, Karol G, Leslie Grace y más - eleconomistaamerica.com [ElEconomista.es]. Recuperado el 21 de octubre de 2018, de https://www.economiahoy. $\mathrm{mx} /$ ocio/noticias/8986792/03/18/Las-mujeres-delreggaeton-Becky-G-Karol-G-Leslie-Grace-y-mas.html

Simmel, G. (1999). La coquetería. En G. Dieterich (Trad.), Cultura femenina y otros ensayos (pp. 115-138). Barcelona: Alba.

Ubilluz, J. C. (2006). El perreo: la perversión hecha mercancía. En Nuevos súbditos: cinismo y perversión en la sociedad contemporánea (pp. 93-118). Lima: IEP.

Villanueva, C. F. (1998). El arte de amar: un análisis sociológico. REIS, (84), 125-146. https://doi. org/10.2307/40184079

Zambra, A. (2011). Formas de volver a casa. Barcelona: Anagrama. 